Patricia K. Morley-Forster MD, Donald W. Reid MD, Hilde Vandeberghe PhD

\section{A comparison of patient-controlled anal- gesia fentanyl and alfentanil for labour analgesia}

Purpose: To determine the analgesic efficacy of equipotent doses of PCA (patient-controlled analgesia) fentanyl and PCA alfentanil for labour pain.

Methods: Twenty three, ASA I - II parturients between 32-42 wk gestational age in whom epidural analgesia was contraindicated were randomized to receive PCA fentanyl (Group F)or alfentanil (Group A). Plain numbered vials contained $2 \mathrm{I} \mathrm{ml} \mathrm{fentanyl} 50 \mu \mathrm{g} \cdot \mathrm{ml}^{-1}$ or alfentanil $500 \mu \mathrm{g} \cdot \mathrm{ml}^{-1}$. A one millilitre loading dose was administered. The PCA solution was prepared by diluting $10 \mathrm{ml}$ study drug with $40 \mathrm{ml}$ saline and the PCA pump was programmed to deliver a dose of $2 \mathrm{ml}$, delay of five minutes and a basal rate of $2 \mathrm{ml} \cdot \mathrm{hr}^{-1}$. Maternal measurements obtained were hourly drug dose, total dose, Visual Analog Pain Score (VAPS) q 30 min, sedation score q I hr and side effects. Neonates were assessed by 1,5, and 10-min Apgar scores, umbilical venous and arterial blood gases and neurobehavioural scores at four and $24 \mathrm{hr}$.

Results: Mean VAPS from $7-10 \mathrm{~cm}$ cervical dilatation were higher in Group A than in Group F. $85.7 \pm 13.9$ vs $64.6 \pm 12.1 ; P<0.01$ ) There were no inter-group differences in VAPS from I - $3 \mathrm{~cm}$, or from $4-6 \mathrm{~cm}$ dilatation, in maternal sedation scores or side effects, or in neonatal outcomes.

Conclusion: In the doses prescribed in this study, PCA fentanyl was found to provide more effective analgesia in late first stage labour than PCA alfentanil.

Objectif : Déterminer l'efficacité analgésique de doses équivalentes de fentanyl ACP (analgésie contrôlée par le patient) et d'alfentanil ACP pendant le travail obstétrical.

Méthode : Vingt-trois parturientes, ASA I-II, de 32 à 42 sem de grossesse, réparties au hasard et pour qui l'analgésie péridurale était contre-indiquée, ont reçu du fentanyl (groupe F) ou de l'alfentanil (groupe A) ACP. Le contenu de flacons simples, numérotés, de $2 \mathrm{I} \mathrm{ml} \mathrm{de} \mathrm{fentanyl} \mathrm{à} 50 \mu \mathrm{g} \cdot \mathrm{ml}^{-1}$ ou d'alfentanil à $500 \mu \mathrm{g} \cdot \mathrm{ml}^{-1}$ et un millilitre de dose de charge ont été administrés. La solution d'ACP comportait $10 \mathrm{ml}$ du médicament à l'étude dilués dans $40 \mathrm{ml}$ de solution salée et la pompe d'ACP a été programmée pour une dose de $2 \mathrm{ml}$, un délai de cing minutes et une vitesse de base de $2 \mathrm{ml} \cdot \mathrm{hr}^{-1}$. On a fait les mesures suivantes : la dose de médicament à chaque heure, la dose totale, le score de l'échelle visuelle analogique (SEVA) aux $30 \mathrm{~min}$, le score de sédation aux heures et les effets secondaires. Chez les nouveau-nés on a noté l'indice d'Apgar à I, 5 et 10 min, les gaz du sang artériel et veineux du cordon et les scores neurologiques à $4 \mathrm{~h}$ et $24 \mathrm{~h}$.

Résultats : Les SEVA moyens pour une dilatation cervicale de $7-10 \mathrm{~cm}$ ont été plus élevés dans le groupe A que dans le groupe $F(85,7 \pm 13,9$ vs $64,6 \pm 12,1 ; P<0,01)$. II n'y a pas eu de différence intergroupe concernant les SEVA pour une dilatation de $1-3 \mathrm{~cm}$ ou de $4-6 \mathrm{~cm}$, les scores de sédation de la mère ou les effets secondaires, ou l'évolution des nouveau-nés.

Conclusion : Selon les doses prescrites dans notre étude, le fentanyl ACP a été un analgésique plus efficace, à la fin du premier stade du travail obstétrical, que l'alfentanil ACP.

From the Departments of Anaesthesia and Neonatology, St. Joseph's Health Centre, University of Western Ontario, Canada. Address correspondence to: Dr. Pat Morley-Forster, Department of Anaesthesia, St. Joseph's Health Centre, 268 Grosvenor St, London, Ontario, N6A 4V2 Canada. Phone: 519-646-6100, x64219; Fax: 519-646-6116; E-mail: pmorleyf@julian.uwo.ca

Presented at the Society for Obstetric Anesthesia and Perinatology Meeting, Bermuda, 1997. Accepted for publication November 6, 1999 
HERE is a need for an acceptable alternative to epidural analgesia for pain relief in labour for a number of reasons. An epidural may be contraindicated due to coagulopathy, infection, spinal abnormalities or severe maternal anxiety about the procedure. In many communities, due to limited anesthesia personnel, a $24 \mathrm{hr}$ epidural service is not feasible. The traditional alternative has been intramuscular meperidine. Although moderately effective, meperidine is accompanied by a higher incidence of maternal nausea and sedation and neonatal respiratory depression than fentanyl. ${ }^{1}$

Patient-controlled analgesia (PCA) fentanyl has been used as an alternative method of pain relief in labour when epidural analgesia is contraindicated. . $^{2-4}$ According to our observations, supported by Rosaeg et al., this technique does not always provide adequate pain relief for the intense pain of late first stage labour. One of the reasons for this is that fentanyl does not reach its maximum clinical effect for up to six minutes after a bolus injection. ${ }^{5}$ Alfentanil via the PCA route has been used as an intraoperative analgesic in outpatients undergoing painful diagnostic procedures. ${ }^{6}$ With its rapid onset and offset, alfentanil may offer more effective labour analgesia than fentanyl. This is the first report of a prospective, randomized doubleblind clinical trial in parturients comparing the analgesic efficacy of equipotent doses of PCA fentanyl with PCA alfentanil.

\section{Methods}

The study protocol was approved by the Institutional Review Board. Written informed consent was obtained from women over the age of $18 \mathrm{yr}$ with a medical contraindication to epidural analgesia. If the contraindication was present before the onset of labour, consent was obtained in the Obstetrical Preadmission Clinic or on the Antenatal Ward. Exclusion criteria were inability to communicate in English, maternal weight $>100 \mathrm{Kg}$ or $<50 \mathrm{Kg}$, gestational age $<32 \mathrm{wk}$, abnormal fetal heart tracing and history of opioid abuse.

At the time of their first request for analgesia, patients were randomized to receive either PCA fentanyl (Group F) or PCA alfentanil (Group A) in a blinded fashion according to a randomization schedule prepared by Pharmacy. For purposes of this study, the analgesic potency of fentanyl: alfentanil was assumed to be 10:1. ${ }^{7}$ Plain numbered vials containing $21 \mathrm{ml}$ of either $50 \mu \mathrm{g} \cdot \mathrm{ml}^{-1}$ fentanyl or $500 \mu \mathrm{g} \cdot \mathrm{ml}^{-1}$ alfentanil were prepared by Pharmacy. The anesthesiologist prepared the PCA solution by diluting $10 \mathrm{ml}$ study drug with $40 \mathrm{ml}$ saline to produce a solution of either $10 \mu \mathrm{g} \cdot \mathrm{ml}^{-1}$ fentanyl or $100 \mu \mathrm{g} \cdot \mathrm{ml}^{-1}$ alfentanil. Both groups received a one millilitre intravenous bolus dose of the assigned opioid administered by the attending anesthesiologist. Group F patients received $50 \mu \mathrm{g}$ fentanyl $i v$; Group A patients received $500 \mu \mathrm{g}$ alfentanil $i v$. For all patients, the Bard II PCA pump was programmed to deliver a dose of $2 \mathrm{ml}$ with a delay of five minutes and a basal rate of $2 \mathrm{ml} \cdot \mathrm{hr}^{-1}$. The maximal hourly rate was set at $26 \mathrm{ml}$. The PCA pump was discontinued by the attending labour nurse when the time to delivery was estimated to be $15 \mathrm{~min}$, usually when the infant's head was one centimetre below the ischial spines. The actual time in minutes from discontinuation to delivery was noted.

A printout was obtained from the PCA machine showing the hourly drug dose, number of attempts and total dose administered.

The primary outcome of maternal pain was measured subjectively by $100 \mathrm{~mm}$ Visual Analog Pain Scores (VAPS) done at baseline, prior to commencement of the PCA and every 30 min thereafter. The woman was asked to grade the pain experienced with the previous contraction. Maternal side effects of nausea, vomiting, dizziness and sedation were recorded hourly by the attending nurse by asking the mother to mark a $100 \mathrm{~mm}$ Visual Analog Sedation Scale (VASS) with 0 being "Wide Awake" and 100 being "Unable to keep eyes open". Vaginal examinations to assess the progress of labour were conducted approximately every two to four hours at the discretion of the attending obstetrician. The cervical dilatation was recorded beside the pain score if the examination had been performed in the preceding $30 \mathrm{~min}$. If not, the dilatation at the time of the pain score was estimated from the Friedman curve of labour which was constructed for each patient. To compare the analgesic efficacy at similar pain intensities, the mean VAPS for each group were compared at the ranges of 1 - 3, $4-6$, and $7-10 \mathrm{~cm}$ of dilatation. After delivery, both the mother and the attending nurse were asked to rate the level of pain relief provided by the PCA as good, adequate or inadequate. The mother was also asked if she would use this method of pain relief in labour again, if she were unable to have an epidural.

The Apgar scores at one, five and ten minutes, umbilical venous and arterial blood gases, and neonatal naloxone dose, if required, were all recorded. One neonatologist (DR), blinded to group assignment, rated neurobehavioural scores at four and $24 \mathrm{hr}$ of life using the Neurologic and Adaptive Capacity Score described by Amiel-Tison. ${ }^{8}$ If the infant was delivered by Cesarean section, the Apgar and the neurobehavioural scores were not recorded due to the confounding influence of the general anesthetic. 
Five millilitres maternal blood and one millilitre umbilical venous blood were drawn immediately after delivery for measurement of serum fentanyl/alfentanil concentrations. Each sample was centrifuged and stored at $-20^{\circ} \mathrm{C}$ until the assay was conducted. The alfentanil and fentanyl concentrations in serum were diluted in sample diluent and analyzed using Alfentanil and Fentanyl SingleStep ELISA kits respectively from Bioman Products Inc. ${ }^{9}$

The wells in the microplate were coated with high affinity capture antibody to alfentanil or fentanyl. The diluted serum was added to the well followed by alfentanil or fentanyl conjugated to horseradish peroxidase enzyme respectively. During the incubation step, the enzyme conjugate competes with the drug in the sample for the binding sites on the antibody-coated well. After a wash step to remove unbound material 3,3',5,5'-tetramethylbenzidine substrate was added for the final colour development. The colour intensity was inversely proportional to the amount of Alfentanil or Fentanyl in the sample. The light absorbance of the samples in the microplate was read on an LP 400 filterphotometer (Diagnostics Pasteur) at $620 \mathrm{~nm}$. A standard curve was made for alfentanil with the following concentrations: $0.1,0.5,1.0,2.5,5.0$, and 10 $\mu \mathrm{g} \cdot \mathrm{L}^{-1}$ and for fentanyl with concentrations of 0.01 , $0.05,0.1,0.25,0.5$, and $1.0 \mu \mathrm{g} \cdot \mathrm{L}^{-1}$. The data reduction used point-to-point curve fitting. The lowest limit of detection of fentanyl was $0.01 \mu \mathrm{g} \cdot \mathrm{L}^{-1}$ and the coefficient of variation was less than $10 \%$.

Demographic data were analyzed with Student's $t$ test. Maternal pain and sedation scores, Apgar scores, and neonatal neurobehavioural scores between groups were compared using the Wilcoxon two-sample test. To increase the available number of complete sets of observations, cervical dilatation was grouped into three ranges of $1-3 \mathrm{~cm}, 4-6 \mathrm{~cm}$ and $7-10 \mathrm{~cm}$. Mean pain scores were calculated within each of the three ranges prior to the between group comparisons. Pearson correlation was used to measure the association between umbilical drug levels and neonatal characteristics. A $P$ value of $\leq 0.05$ was considered statistically significant. For the maternal sedation scores, measured at one hour intervals, a significance level of 0.01 was set to adjust for multiple testing.

Results

Twenty-five patients were enrolled; two were withdrawn for failure to follow the study protocol leaving 23 mothers and 24 neonates for analysis. There were 11 parturients in the fentanyl group and 12 in the alfentanil group. The reason for medical contraindication to an epidural was coagulopathy in all but two
TABLE I Maternal demographics

\begin{tabular}{lll}
\hline & $\begin{array}{l}\text { Group } F \\
(n=11)\end{array}$ & $\begin{array}{l}\text { Group } A \\
(n=12)\end{array}$ \\
\hline Maternal Age $(\mathrm{yr})$ & $25.4 \pm 5.2$ & $26.9 \pm 2.5$ \\
Maternal Wt $(\mathrm{kg})$ & $81.2 \pm 13.5$ & $80.1 \pm 13.2$ \\
Gest. Age $(\mathrm{wk})$ & $38.9 \pm 2.3$ & $37.8 \pm 2.6$ \\
Primiparous & 9 & 10 \\
Inductions & 6 & 7 \\
C-Sections & 3 & 2 \\
Rate of Dilatation $\left(\mathrm{cm} \cdot \mathrm{hr}^{-1}\right)$ & $1.8 \pm 1.6$ & $2.1 \pm 1.4$ \\
Baseline VAS Pain $(\mathrm{mm})$ & $65.1 \pm 19.1$ & $67.3 \pm 31.4$ \\
PCA Duration $(\mathrm{min})$ & $313 \pm 172$ & $355 \pm 347$ \\
Fentanyl $(\mu \mathrm{g})$ & $852 \pm 552$ & \\
Alfentanil $(\mu \mathrm{g})$ & & $8840 \pm 7294$ \\
Last Dose - Delivery $(\mathrm{min})$ & $39.2 \pm 21.6$ & $17 \pm 14.9 *$ \\
Drug Consumption $\left(\mu \mathrm{g} \cdot \mathrm{kg}^{-1} \cdot \mathrm{min}\right)$ & $0.034 \pm .01$ & $0.36 \pm .10$ \\
\hline
\end{tabular}

Values are mean \pm S.D. ${ }^{*} P<0.05$

Comparison of demographic data of the mothers who received PCA Fentanyl (Group F) and those who received PCA Alfentanil (Group A). The only difference was that the last dose - delivery interval was shorter in the PCA Alfentanil group.

TABLE II Maternal visual analog pain scores

\begin{tabular}{lll}
\hline & Group F & Group A \\
\hline VAPS @ $1-3 \mathrm{~cm}$ & $61.0 \pm 19.6(\mathrm{n}=9)$ & $67.3 \pm 29.2(\mathrm{n}=10)$ \\
VAPS @ 4 - 6 cm & $54.9 \pm 24.9(\mathrm{n}=11)$ & $67.7 \pm 20.2(\mathrm{n}=10)$ \\
VAPS @ $7-10 \mathrm{~cm}$ & $64.6 \pm 12.2(\mathrm{n}=7)^{*}$ & $85.7 \pm 13.9(\mathrm{n}=12)^{*}$ \\
\hline
\end{tabular}

Values are mean \pm S.D. ${ }^{*} P<0.01$

Comparison of mean Visual Analog Pain Scores between patients receiving PCA Fentanyl and those receiving PCA Alfentanil. In order to compare analgesic efficacy at similar pain intensities, the mean scores at $1-3 \mathrm{~cm}, 4-6 \mathrm{~cm}$ and $7-10 \mathrm{~cm}$ of cervical dilatation were compared. Since some women did not request PCA until 6 to $7 \mathrm{~cm}$ dilatation and some required a Cesarean section for dystocia at 5 to $6 \mathrm{~cm}$, the sample size varied from cell to cell.

TABLE III Maternal visual analog sedation scores

\begin{tabular}{lll}
\hline & Group F & Group A \\
VASS @ $1 \mathrm{hr}$ & $65.5 \pm 25.4(\mathrm{n}=11)$ & $44.8 \pm 26.0(\mathrm{n}=11)$ \\
VASS $@ 2 \mathrm{hr}$ & $79.2 \pm 16.0(\mathrm{n}=9)$ & $59.8 \pm 28.4(\mathrm{n}=8)$ \\
VASS @ $3 \mathrm{hr}$ & $81.3 \pm 16.8(\mathrm{n}=8)$ & $69.8 \pm 32.5(\mathrm{n}=6)$ \\
VASS $94 \mathrm{hr}$ & $69.9 \pm 33.5(\mathrm{n}=7)$ & $69.1 \pm 21.3(\mathrm{n}=5)$ \\
VASS @ $5 \mathrm{hr}$ & $79.3 \pm 22.4(\mathrm{n}=4)$ & $71.5 \pm 39.2(\mathrm{n}=4)$ \\
VASS $@ 6 \mathrm{hr}$ & $89.5 \pm 13.7(\mathrm{n}=4)$ & $66.0 \pm 45.5(\mathrm{n}=4)$ \\
\hline
\end{tabular}

Values are mean \pm S.D.

Mean Visual Analogue Sedation Scale at 1,2,3,4,5 and 6 hours after the PCA was started. 0 indicates "wide awake" while 100 indicates "too drowsy to keep eyes open". There was no difference in the level of sedation between groups.

patients; one of these had Harrington spinal rods, the other was needle-phobic.

The two groups were similar in age, weight, gestational age, parity, inductions, type of delivery, baseline pain scores, rate of cervical dilatation, duration of PCA 
TABLE IV Maternal pain questionnaires

\begin{tabular}{lllll}
\hline & $\begin{array}{c}\text { Group } F \\
(n=11)\end{array}$ & \multicolumn{2}{c}{$\begin{array}{c}\text { Group A } \\
(n=12)\end{array}$} \\
& Good/Adequate & Inadequate & Good/Adequate & Inadequate \\
\hline Maternal Rating of Pain Relief & $10(91)$ & $1(9)$ & $7(58)$ & $5(42)$ \\
Nurse's Rating of Pain Relief & $10(91)$ & $1(9)$ & $9(75)$ & $3(25)$ \\
\hline
\end{tabular}

The numbers in parentheses indicate percent.

The mother was asked within six hours of delivery "Overall how would you rate this method of pain relief? Good - Adequate -

Inadequate". There was no difference between the groups.

The questionnaire to the nurse asked "How would you rate this patient's pain relief? Good -Adequate - Inadequate." There was no difference between groups.

TABLE V Neonatal characteristics

\begin{tabular}{|c|c|c|c|c|}
\hline & $\begin{array}{c}\text { Group F } \\
(n=11)\end{array}$ & & $\begin{array}{l}\text { GROUP } A \\
(n=13)\end{array}$ & \\
\hline Weight $(\mathrm{g})$ & $3064 \pm 77$ & & $2949 \pm 55$ & \\
\hline Gest. Age (wk) & $38.9 \pm 2.3$ & & $37.8 \pm 2.5$ & \\
\hline C-Section & 3 & & 2 & \\
\hline APGAR I (median / range) & $6 / 4-9$ & & $8 / 4-9$ & \\
\hline APGAR 5 (median/range) & $9 / 6-9$ & & $9 / 1-9$ & \\
\hline APGAR 10 (median/range) & $9 / 8-10$ & & $9 / 6-10$ & \\
\hline 4 hr NACS (median/ range) & $36 / 23-40$ & $(\mathrm{n}=8)$ & $35 / 16-40$ & $(\mathrm{n}=9)$ \\
\hline 24 hr NACS (median/range) & $36 / 25-39$ & $(\mathrm{n}=8)$ & $38 / 18-40$ & $(\mathrm{n}=9)$ \\
\hline No. Given Naloxone & 4 & $(36.4 \%)$ & 2 & $(15.4 \%)$ \\
\hline Umbilical Ven. pH & $7.29 \pm .04^{*}$ & & $7.33 \pm .05^{*}$ & \\
\hline
\end{tabular}

Values are mean \pm S.D. ${ }^{*} P<.05$

Comparison of the characteristics of the neonates whose mothers received PCA Fentanyl (Group F) to those whose mothers received PCA Alfentanil (Group A). If the neonate was delivered by Cesarean section, Apgar and neurobehavioural scores (NACS) were not recorded due to the confounding influence of the general anesthetic. The only difference between groups was in the umbilical venous $\mathrm{pH}$.

However, when only the neonates delivered vaginally were compared, this difference disappeared.

TABLE VI Maternal and umbilical venous serum concentrations

\begin{tabular}{|c|c|c|c|c|c|}
\hline $\begin{array}{l}\text { Patient } \\
\text { Study } \\
\text { Number }\end{array}$ & $\begin{array}{l}\text { Umbilical Venous } \\
\text { Fentanyl } n g \cdot \mathrm{ml}^{-1} \\
(n=9)\end{array}$ & $\begin{array}{l}\text { Maternal } \\
\text { Fentanyl } n g \cdot \mathrm{ml}^{-1} \\
(n=9)\end{array}$ & $\begin{array}{l}\text { Umbilical Venous } \\
\text { Alfentanil } n g \cdot m t^{-1} \\
(n=8)\end{array}$ & $\begin{array}{l}\text { Maternal } \\
\text { Alfentanil } \\
n g \cdot m^{-1}(n=8)\end{array}$ & $\begin{array}{l}\text { Fetal/Maternal } \\
\text { Ratio }\end{array}$ \\
\hline 1 & 1.189 & 1.927 & & & 0.62 \\
\hline 2 & 0.574 & 1.886 & & & 0.3 \\
\hline 5 & 1.066 & 0.574 & & & 1.86 \\
\hline 6 & 1.066 & 0.738 & & & 1.44 \\
\hline 7 & 0.82 & 0.533 & & & 1.54 \\
\hline 8 & 0.205 & $<0.123$ & & & 1.67 \\
\hline 9 & 0.123 & 0.451 & & & 0.27 \\
\hline 10 & 0.943 & 1.353 & & & 0.7 \\
\hline 11 & 0.574 & 1.804 & & & 0.32 \\
\hline 12 & & & $<4.1$ & 54.69 & 0.07 \\
\hline 13 & & & 4.26 & 19.72 & 0.22 \\
\hline 15 & & & $<4.1$ & 28.82 & 0.14 \\
\hline 16 & & & 13.33 & 60.6 & 0.22 \\
\hline 17 & & & & 64.12 & \\
\hline 18 & & & 6.15 & 27.8 & 0.22 \\
\hline 19 & & & 12.46 & 59.41 & 0.21 \\
\hline 21 & & & 31.24 & 92.7 & 0.34 \\
\hline
\end{tabular}


use. The only difference was that the opioid dose- todelivery time was shorter in the alfentanil group. The total fentanyl doses ranged from $292-1,686 \mu$ g while the total alfentanil doses ranged from $2,620 \mu \mathrm{g}$ to $21,540 \mu \mathrm{g}$.

Since some women did not request PCA until 6 to $7 \mathrm{~cm}$ of dilatation while some required a Cesarean section for dystocia at 5 to $6 \mathrm{~cm}$, the sample size varied from cell to cell. There were no inter-group differences in Visual Analog Pain Scores (VAPS) from 1 to 3 or from 4 to $6 \mathrm{~cm}$ of dilatation. However, the mean VAPS at 7 to $10 \mathrm{~cm}$ dilatation were higher in the alfentanil group than in the fentanyl group (Table II).

The maternal Visual Analog Sedation Scores (VASS) displayed in Table III showed no difference between groups. The incidence of nausea in Group $\mathrm{F}$ was $45 \%$ and $17 \%$ in Group A ( $P: N S)$; the incidence of pruritus was $15 \%$ in Group F and $7.5 \%$ in Group A (P:NS).

Forty-two percent of mothers receiving alfentanil described the pain relief as inadequate compared with 9\% in the fentanyl group but this did not attain statistical significance due to the small number in each cell. Seventy-three percent of mothers receiving fentanyl would use this method of pain relief in labour again but only $33 \%$ in the alfentanil group would request it again. Interestingly, from the nurses' perspective, both methods were similar in efficacy (Table IV).

There were no differences between the neonates in the two groups with regard to weight, gestational age, type of delivery, Apgar scores, neurobehavioural scores, umbilical venous $\mathrm{pH}$ or naloxone requirement (Table V).

Maternal and neonatal fentanyl /alfentanil levels are displayed in Table VI. Blood samples were only collected on nine subjects in the fentanyl group and eight in the alfentanil group. The high mean fetal/maternal $(\mathrm{F} / \mathrm{M})$ ratio of 0.97 in the fentanyl group compared with the $\mathrm{F} / \mathrm{M}$ ratio of 0.2 in the alfentanil group is a reflection of the higher lipid solubility of fentanyl. There was no correlation between maternal drug concentration and PCA duration. The umbilical venous drug concentration was not correlated with total fentanyl administered, with one-,five- or ten- minute Apgar scores or with neurobehavioural scores. In four subjects the maternal fentanyl level was below the minimum effective analgesic concentration (MEAC) of $0.63 \mathrm{ng} \cdot \mathrm{ml}^{-1}$ as determined by Gourlay et al. ${ }^{0}$ All patients in the alfentanil group had a maternal serum concentration greater than $14.9 \mathrm{ng} \cdot \mathrm{ml}^{-1}$, the MEAC of alfentanil. ${ }^{11}$
Discussion

The most surprising finding of this study was that despite the rapid onset of alfentanil it did not prove as effective for PCA analgesia in labour as fentanyl. There are several possible reasons for this observation. First, the doses used may not have been equipotent. The reported potency of alfentanil varies widely in the literature depending on the end-point and on whether a single intravenous bolus or steady-state serum concentration model was used. ${ }^{5}$ White and colleagues found a dose ratio varying from 1:6 to $1: 40$ when comparing single boluses of fentanyl and alfentanil for outpatient anesthesia. ${ }^{12}$ In a study of PCA alfentanil after major abdominal and orthopedic procedures, Lehmann and co-workers determined that alfentanil was $1 / 15$ th as potent as fentanyl taking into account both intensity and duration of effect. ${ }^{10}$ If this figure is correct, then the alfentanil patients may have been receiving less than equipotent doses.

However, if the ratio is closer to $4: 1$, as stated in early studies of alfentanil, ${ }^{13}$ then the doses of alfentanil were overly generous in comparison to those of fentanyl and should have proven more effective. In support of a 10:1 potency ratio, the mean drug consumption per minute measured in this trial was almost exactly ten times higher in the alfentanil group.

Another possibility is that through metabolism or redistribution, the serum concentration of alfentanil had decreased below the minimum effective analgesic concentration (MEAC) before the next contraction.

There is little data in the literature that refer to serum concentrations that provide analgesia in the conscious patient. To determine the MEAC of alfentanil for labour analgesia, one would need to draw a maternal venous sample prior to a self-administered bolus. Using this method, Lehmann and colleagues determined that the MEAC of alfentanil for postoperative analgesia varied greatly with a range of 0.6 to $99.2 \mathrm{ng} \cdot \mathrm{ml}^{-1}$ and a median level of $14.9 \mathrm{ng} \cdot \mathrm{ml}^{-1} .{ }^{10}$ The eight patients in our study in whom serum alfentanil concentrations were analyzed at delivery all demonstrated levels well above this value despite the average time from last dose to delivery being $17 \pm$ $14.9 \mathrm{~min}$. The pain stimulus of a labour contraction may well require higher serum concentrations for analgesia than those required for postoperative analgesia after abdominal surgery.

The pharmacokinetic behaviour of alfentanil has been well-described. ${ }^{14}$ Alfentanil has a much shorter elimination half-life than fentanyl $(90 \mathrm{~min}$ vs six hours) but its termination of action, as with fentanyl, is by redistribution. Its initial volume of distribution is seven-fold smaller than that of fentanyl due to its 
lower lipid solubility so that a higher serum concentration should be reached more rapidly.

The third possibility is that the sedating qualities of fentanyl offer an improved quality of analgesia over alfentanil. Fentanyl was associated with higher maternal drowsiness scores throughout the study but, due to small numbers, this did not reach statistical significance.

There was no reason to suspect that the degree of maternal pain was higher in the alfentanil group since the number of primiparous patients, inductions, rate of dilatation and baseline pain scores were equally distributed between groups.

One weakness of this study is that the design utilized a single fixed dosage regimen not allowing titration to effect. A higher basal infusion rate and shorter lock-out interval may have been a more appropriate way to deliver alfentanil. The dosing parameters for alfentanil in this trial were drawn from a study by Chauvin et al. who compared the efficacy of intravenous and epidural alfentanil for postoperative analgesia following major abdominal surgery. ${ }^{15}$

The risk of causing neonatal respiratory depression is one of the major concerns when an opioid is administered to women in labour. Both fentanyl and alfentanil are rapidly transferred across the placenta and both are highly bound to alpha-1 acid glycoprotein $\left(\alpha_{1}-\right.$ AGP). Since the neonatal level of $\alpha_{1}$ - AGP is lower than adults, there is more free drug available to traverse the infant's blood-brain barrier. ${ }^{16}$

In the judgement of the attending neonatologist, four of 11 neonates in the fentanyl group and two of 13 in the alfentanil group required naloxone, a clinically significant number, though not statistically different. The important predictor of neonatal depression was whether the mother had received a general anesthetic for Cesarean section although pump time and opioid dose approached significance $(P=0.076),(P=0.087)$.

The incidence of depression after fentanyl labour analgesia in term infants varies from 0 to $2 \% .^{4,1}$ In Nikkola's study of 20 patients randomized to receive either epidural analgesia or PCA fentanyl at doses similar to those in our trial, all babies were vigorous at delivery. However, these investigators did not allow any fentanyl in the second stage resulting in a mean last dose-to-delivery interval of $92 \pm 81 \mathrm{~min}$. Despite the lack of visible depression at birth, the fentanyl neonates had more events of $\mathrm{SpO}_{2} \leq 90 \%$ over the subsequent $12 \mathrm{hr}$ monitoring period.

The average last dose-to-delivery time in the fentanyl group was $39.2 \pm 21.6 \mathrm{~min}$ and, in the alfentanil group, was $17 \pm 14.9 \mathrm{~min}$. Would we have seen less neonatal depression had we prevented access to the
PCA in second stage? The literature, although scanty, does not support this. In a retrospective review from this institution of 32 infants whose mothers had received PCA fentanyl, there were three infants who needed naloxone. ${ }^{17}$ In addition, in this high-risk obstetric population, PCA fentanyl was associated with a $44 \%$ incidence of moderately depressed neonates with an Apgar score $<6$ at one minute. The time from last PCA dose-to-delivery was not a predictor of neonatal depression but the total maternal dose of fentanyl was. Based on this information, our protocol allowed the mother to continue benefitting from the PCA until the time to delivery was estimated to be $15 \mathrm{~min}$.

There was no measurable difference between groups in maternal side effects perhaps due to the small sample size. The incidence of nausea was low in both groups and a power analysis revealed that to detect a true difference in nausea would require 75 patients per group.

In a comparison of epidural analgesia with PCA fentanyl, Nikkola et al. found that one third of the patients assigned to the fentanyl group eventually crossed over to the epidural group due to inadequate analgesia. ${ }^{4}$ This number is similar to the $42 \%$ crossover rate seen by Muir et al. ${ }^{18}$ Both for ethical reasons and to avoid this high dropout rate, we chose a population in whom epidural analgesia was medically contraindicated. The difficulty with this selection policy was that suitable patients were rare and usually could not be anticipated. It took over three years to enrol the 23 patients in this study. Despite the small numbers, the difference in pain scores in late labour is highly significant. To detect a difference in pain scores between groups at 4 to $6 \mathrm{~cm}$ dilatation with $80 \%$ power would require a sample size of 32 patients/group.

In conclusion, the Visual Analog Pain Scores indicate that neither the fentanyl or the alfentanil group received effective analgesia. However, in the doses prescribed in this study, PCA fentanyl provided superior labor analgesia to PCA alfentanil with no difference in maternal side effects. The risk of neonatal respiratory depression when either opioid is administered in labour must be recognized.

\section{Acknowledgments}

The authors gratefully acknowledge the cooperation of the nursing and anesthesia staff of the Family Birthing Centre at St. Joseph's Health Centre in gathering the data. We would also like to thank Mr. Larry Stitt of the Biostatistics and Epidemiology Department for statistical analysis and Mrs. Angela Grieve for expert secretarial assistance. 


\section{References}

1 Rayburn WF, Smith CV, Parriott JE, Woods RE. Randomized comparison of meperidine and fentanyl during labor. Obstet Gynecol 1989; 74: 604-6.

2 Kleiman SJ, Wiesel S, Tessler MJ. Patient-controlled analgesia (PCA) using fentanyl in a parturient with a platelet function abnormality. Can J Anaesth 1991; 38 : 489-91.

3 Rosaeg OP, Kitts JB, Koren G, Byford LJ. Maternal and fetal effects of intravenous patient-controlled fentanyl analgesia during labour in a thrombocytopenic parturient. Can J Anaesth 1992; 39: 277-81.

4 Nikkola EM, Ekblad UU, Kero PO, Alibanka JJM, Salonen MAO Intravenous fentanyl PCA during labour. Can J Anaesth 1997; 44: 1248-55.

5 Scott JC, Ponganis KV, Stanski DR EEG quantitation of narcotic effect: the comparative pharmacodynamics of fentanyl and alfentanil. Anesthesiology 1985; 62: 234-41.

6 Zelcer J, White PF, Chester S, Paull JD, Molnar R Intraoperative patient-controlled analgesia: an alternative to physician administration during outpatient monitored anesthesia care. Anesth Analg 1992; 75: 41-4.

7 Barash PG, Cullen BF, Stoelting RK Clinical Anesthesia, 2nd ed. Philadelphia: J.B. Lippincott Company, 1992: 417.

8 Amiel-Tison C, Barrier G, Shnider SM, Levinson G, Hughes SC, Stefani SJ. A new neurologic and adaptive capacity scoring system for evaluating obstetric medications in full-term newborns. Anesthesiology 1982; 56: 340-50.

9 Vandeberghe $H$. Feasibility of quantitation of serum alfentanil using a qualitative kit. Abstracts Fifth International Congress of Therapeutic Drug Monitoring and Clinical Toxicology 1997: Vancouver.

10 Gourlay GK, Kowalski SR, Plummer JL, Cousins MJ, Armstrong PJ. Fentanyl blood concentration - analgesic response relationship in the treatment of postoperative pain. Anesth Analg 1988; 67: 329-37.

11 Lebmann KA, Ribbert N, Horrichs-Haermeyer G Postoperative patient-controlled analgesia with alfentanil: analgesic efficacy and minimum effective concentrations. J Pain Symptom Manage 1990; 5: 249-58.

12 White PF, Coe V, Shafer A, Sung M-L. Comparison of alfentanil with fentanyl for outpatient anesthesia.

Anesthesiology 1986; 64: 99-106.

13 Bovill JG, Sebel PS, Blackburn CL, Heykants J. The pharmacokinetics of alfentanil (R39209): a new opioid analgesic. Anesthesiology 1982; 57: 439-43.

14 Hull CJ. The pharmacokinetics of alfentanil in man. $\mathrm{Br}$ J Anaesth 1983; 55: 157S-64.

15 Chauvin M, Hongnat JM, Mourgeon E, Lebrault C, Bellenfant $F$, Alfonsi P. Equivalence of postoperative analgesia with patient-controlled intravenous or epidural alfentanil. Anesth Analg 1993; 76: 1251-8.

16 Gepts E, Heytens L, Camu F. Pharmacokinetics and placental transfer of intravenous and epidural alfentanil in parturient women. Anesth Analg 1986; 65: 1155-60.

17 Morley-Forster PK, Weberpals J. Neonatal effects of patient-controlled analgesia using fentanyl in labor. Int J Obstet Anesth 1998; 7: 103-7.

18 Muir HA, Breen T, Campbell DC, Halpern S, Blanchard $W$. Is intravenous PCA fentanyl an effective method for providing labor analgesia? Abstracts of the Society of Obstetric Anesthesia and Perinatology 1999: A28. 